\title{
The importance of wine attributes in an emerging wine-producing country
}

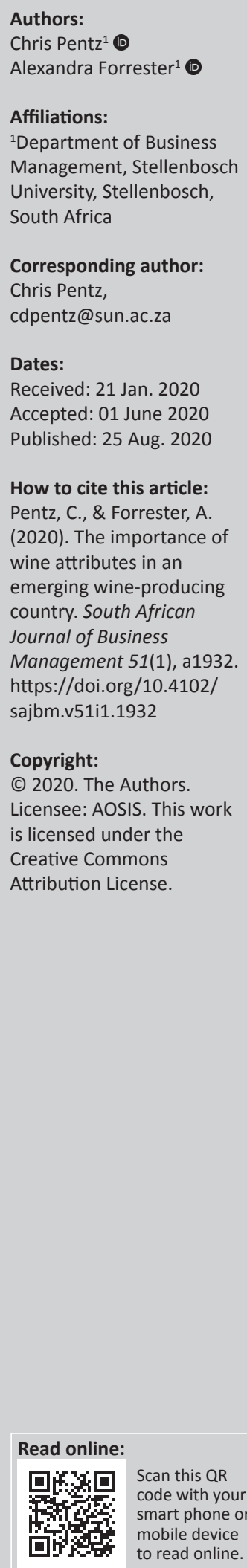

Purpose: This article investigated and compared the relative importance of 14 wine attributes on the wine-purchasing behaviour of South African consumers of different generational groups.

Design/methodology/approach: Data were collected from 646 South African wine consumers by means of a structured online questionnaire. Respondents were divided into two main age groups, 18-40 years of age and 41 years and older. Data analysis included descriptive statistics, best-worst scaling and independent sample $t$-tests.

Findings/results: Results showed that there were both similarities and differences in the relative importance of wine attributes between the two age groups investigated. Both groups regarded the previous tasting of a wine and recommendations by others as the two most important wine attributes when purchasing wine for their own consumption. An in-store promotional display of wines was regarded as the least important wine attribute by the older cohort, whereas an alcohol level below $13 \%$ was rated by the younger cohort as the least important wine attribute.

Practical implications: The findings contribute to a deeper understanding of wine-purchasing behaviour in the emerging wine-producing countries. Results can be used by marketing managers to create more effective marketing strategies to increase wine sales in South Africa amongst different age groups.

Originality or value: This study is a pioneering venture, given the absence of published knowledge on the possible generational differences in the wine consumer behaviour of South Africans.

Keywords: wine attributes; consumer behaviour; South Africa; generational groups; marketing strategies.

\section{Introduction}

Wine has been part of human life for thousands of years. In fact, biomolecular archaeological research suggests that grape wine was first produced during the early Neolithic period in 6000-5000 BC (McGovern et al., 2017). In simple terms, wine can be defined as an alcoholic beverage that results from grape must that undergoes a yeast fermentation process (Fracassetti, Bottelli, Corona, Foschino, \& Vigentini, 2019). Wine is, however, a highly complex and informationintensive product (Ellis \& Thompson, 2018), and its unique composition is influenced by a number of factors, such as oenological techniques, the grape cultivar and climate conditions (Soleas, Diamandis, \& Goldberg, 1997). Owing to the complexity of wine (mainly resulting from various unpredictable attributes) and how these attributes can influence consumer preferences and buying behaviour, it is vital for wine producers and sellers to hone their knowledge in this respect (Pomarici, Lerro, Chrysochou, Vecchio, \& Krystallis, 2017). This knowledge about consumer behaviour can be incorporated into wine-marketing strategies to guide consumers in their winepurchasing decisions.

The wine-purchasing behaviour of consumers has been investigated in several studies, but relatively few of these studies have focused on consumers in emerging markets (Lockshin \& Corsi, 2012; Mehta \& Bhanja, 2018). Lockshin and Corsi (2012) reviewed almost 100 refereed journal articles published between 2004 and 2012 and concluded that whilst emerging markets such as Brazil, Russia, India and China (the so-called BRIC countries) present opportunities for wine producers, it is not generally known whether consumers in emerging markets will behave similarly to those in developed markets when it comes to wine-marketing activities. The authors therefore argue that more scholarly research needs to be conducted on wine consumer behaviour 
in emerging markets. South Africa joined the powerful collaboration of the emerging BRIC countries in December 2010 (South African Government, n.d.) and is regarded as an important role player in the global production of wine.

\section{Background and research objective}

Winemaking in South Africa has been practised for more than 350 years and commenced when Jan van Riebeeck, a Dutch colonial governor, established the first vineyards near the current city of Cape Town (WOSA, 2018). Since then, the South African wine industry has advanced from a small market for domestic consumption to its current status as the ninth largest wine producer in the world, based on 2018 wine production figures (OIV, 2019).

The South African wine industry has experienced consistent growth since the early 2000s, and the country's wine is mainly exported to the United Kingdom (UK), Germany and the Netherlands (Wesgro, 2017). However, the South African wine industry is facing difficult times, and for the past decade, South African grape wine producers have been under severe financial pressure. According to Conradie (2019), wine production expenses in South Africa have increased by $7.4 \%$ annually over the past 10 years. On the other hand, wine prices have remained almost unchanged for a number of years, resulting in a situation where more than $80 \%$ of South African wine producers are operating below a sustainable net income. Should one investigate the local consumption of wine, another troubling fact for wine producers arises. At an estimated amount of $7.47 \mathrm{~L}$ per annum, South Africa's per-capita wine consumption is significantly lower when compared to other wine-producing countries such as France (50.70 L), Italy (44.00 L) and Portugal (58.80 L) (SAWIS, 2018). Furthermore, South African wine consumption statistics for the period 2017 to 2018 show a slight decrease in domestic wine consumption from 4.5 to 4.3 million hectolitres (OIV, 2019). The argument can therefore be made that South African wine producers should put much more effort into informed marketing strategies to increase the domestic consumption of wine in a highly complex and competitive market.

Bruwer, Saliba and Miller (2011) suggest that wine consumption can be increased by introducing the product to younger consumers, especially those in their early to midtwenties. This is also a strategy that South African wine producers can consider, especially as previous studies have shown that wine is no longer a product that is exclusively consumed by older generations, but that the younger generation are also increasingly showing an interest in wine (Chrysochou, Krystallis, Mocanu, \& Lewis, 2012; Fountain \& Lamb, 2011). Furthermore, Marinelli et al. (2014) report that previous studies (Mishra, McNaughton, Bramwell, \& Wadsworth, 2006; Olsen, Thach, \& Nowak, 2007) have found that consumers' drinking habits change as they get older and that wine consumption usually increases with age. In addition, Mishra et al. (2006) argue that there is usually a decrease in the consumption of beer, spirits and flavoured alcoholic beverages as consumers get older, suggesting that there might be an opportunity for wine to be the alcoholic beverage of choice of these older consumers. The argument can therefore be made that if wine marketers introduced consumers to wine at a relatively young age (above the legal drinking age), they might continue to drink wine, and as they get older, their wine consumption would probably increase.

A number of wine researchers (Bruwer, Lesschaeve, \& Campbell, 2012; Chrysochou et al., 2012; Fountain \& Lamb, 2011; McGarry Wolf, Higgins, Wolf, \& Qenani, 2018) have highlighted that the concept of generational cohorts or groups is growing in importance in the field of winemarketing research. The argument is that cohort segmentation is thought to present new and promising opportunities for wine marketers, if possible differences between different age groups are adequately addressed by appropriate marketing strategies. To develop even more effective wine-marketing strategies, wine marketers should consider the fact that consumers in different generational groups portray significant differences in attitudes, perceptions and ultimately behaviour towards wine (Chrysochou et al., 2012; Olsen et al., 2007). Bruwer et al. (2011) and McGarry Wolf et al. (2018), however, argue that even though wine marketers are starting to adopt a generational view of the wine market, generational cohorts are still a much under-researched area.

Before addressing wine consumer behaviour, however, it is important to reflect on the complex product under investigation, namely wine. According to Barber, Almanza and Donovan (2006), the wine product consists not only of the beverage itself but also those aspects, such as the packaging, labelling, information provided on the bottle and brand name, linked to the total product. The different components and/or attributes that constitute the total wine product can be divided into two broad categories, extrinsic and intrinsic attributes (Mehta \& Bhanja, 2018), which play an important role in the wine-selection process of consumers. Intrinsic product attributes refer to the physical characteristics of the actual product (Ellis \& Thompson, 2018) that cannot be changed without changing the product itself (Orth \& Krška, 2002). In the case of wine, intrinsic attributes refer to the actual wine (liquid) itself, the grape variety, aging, colour, taste and percentage level of alcohol by volume (Agnoli, Begalli, \& Capitello, 2011), bouquet, smoothness and the balance of flavours of the specific wine (Ellis \& Thompson, 2018).

Many consumers perceive risk when facing a winepurchasing decision, which often stems from the intrinsic wine attributes, more specifically from the nature of the wine product being an experience product. Wine is an experience product as it is not possible to assess the actual quality of the product until it is consumed (Barber, Dodd, \& Ghiselli, 2008). In other words, unlike most products, wine generally has to be tasted before a judgement and purchasing decision can be made (Barber et al., 2006). Furthermore, each bottle of wine is 
distinct and can differ in taste and/or aroma when compared to other wines, mainly because of each wine's intrinsic attributes (Nissen, 2012).

It can therefore be argued that many consumers tend to focus on the extrinsic (more stable) attributes of wine to assist them in the complex wine-purchasing decision (Histro \& Kuhar, 2015). Extrinsic product attributes are inherent and are usually not part of the actual wine product; they include the wine packaging, price, bottle label, brand name and information on whether the wine received awards or medals (Agnoli et al., 2011).

As a result, it is crucial for wine industry role players to have knowledge of the wine attributes that may influence the consumer's decision when selecting and/or purchasing a wine and to know which attributes have the strongest influence when these decisions are made. Consequently, wine marketers can gain insight into the manner in which consumers make wine selection decisions and can incorporate this insight into their marketing strategies to enhance their wine sales.

Cohen (2009) was instrumental by firstly investigating a broad list of initial wine attributes (collected from the literature and insights from wine experts) and then identifying 13 attributes that can typically influence consumers in a wine selection situation. These specific attributes are: 'promotional display in store'; 'grape variety'; 'origin of the wine'; 'information on the shelf'; 'alcohol level below 13\%'; 'matching food'; 'information on the back label'; 'medal/award'; 'an attractive front label'; 'brand name'; 'someone recommended it'; 'I read about it in a guide'; and 'tasted the wine previously'. Since then, several researchers (e.g. Goodman, 2009; Casini, Corsi, \& Goodman, 2009; Chrysochou et al., 2012) have investigated these attributes that are known to influence consumer purchasing behaviour in respect of wine. In addition to the 13 'commonly used' attributes, Nissen (2012) argues that a further attribute that might be important to investigate in wine-purchasing behaviour is the supposed health benefits of wine. This attribute is deemed to be increasingly important as many consumers have adopted the trend of healthy living by consuming healthier foods and beverages (Higgins \& Llanos, 2015). In this regard, a general perception exists that moderate consumption of wine can be beneficial to consumers' health (Chang, Thach, \& Olsen, 2016). In a study using American respondents, Higgins and Llanos (2015) found that more than $50 \%$ of respondents agreed that the consumption of wine reduces the risk of certain diseases and that wine is a healthy alcoholic beverage. Chang et al. (2016) also conducted a study on wine and health perceptions in the United States of America (USA) and found that millennial respondents were much more concerned about their health than older respondents. More than $80 \%$ of the total sample indicated that they believed red wine in particular was a healthier beverage than beer and spirits.
Should one delve deeper into the concept of age, previous studies have found that, in terms of wine-purchasing behaviour, consumers of different age groups are influenced by different wine attributes when making a wine-purchasing decision (Chrysochou et al., 2012; Hirche \& Bruwer, 2014; Nissen, 2012). In a study on the importance of wine attributes for South African Generation Y consumers, Lategan, Pentz and Du Preez (2017) recommended that future research projects in the South African wine market should focus on generational differences in the behaviour of South African wine consumers surrounding wine purchasing and consumption, given that no published studies could be found on this topic in a South African context. The argument is that a generational comparison can shed light on whether generations differ in relation to their wine selection and consumption behaviour in a South African (emerging market) context and whether possible differences would warrant differential wine-marketing strategies.

The academic rationale for this study is thus to build on previous research and add to the body of knowledge on wine consumer behaviour in emerging countries. The practical contribution of this study lies in the fact that it aims to provide insight to wine industry role players on how to address the wine-purchasing behaviour of different generational groups more effectively and efficiently, with the ultimate aim of increasing the domestic sales of South African wines.

In light of the absence of published knowledge in the public domain on the possible generational differences in the wine consumer behaviour of South Africans, this study can be regarded as a pioneering endeavour. Owing to the exploratory nature of the study, the decision was made to first focus on two main generational cohorts, namely a younger cohort (ages 18-40) and an older cohort (ages 41 and up). Apart from the argument that this split into two broad age groups was done because of the exploratory nature of the study, there were also other reasons to justify this decision. In a Marketing News article by Murphy (1999), Gillespie (then president of the Wine Market Council) proclaimed that by the age of 40, most Americans have established their wine-drinking habits. Based on this insight, the decision was made to split the South African sample for this study into two age groups one group on either side of 40 years of age. Furthermore, Casini et al. (2009) conducted a novel study on consumer wine preference in Italy, where they divided their sample into three age groups, namely 18-40, 41-55 and older than 55 years. The results of the study, however, clearly indicated that there were differences between what they regarded as young consumers (18-40) and older consumers (41 and older). The results also pointed out that in on-premise settings (e.g. a restaurant), the younger respondents were more interested in wines with higher alcohol levels than older respondents and that the younger respondents were also more adventurous and willing to experiment with unknown wines than their older counterparts. In a more recent study, Hirche and Bruwer (2014) investigated product involvement 
and also referred to a younger group (18-40 years old) and an older group (older than 40 years). The results showed that the label, package design, promotion, alcohol level, awards / medals and information on the back label of a wine bottle were more important for the younger respondents than for the older respondents.

Therefore, this study aimed to investigate and compare the wine attributes that influence wine-purchasing behaviour between two broad generational groups in South Africa.

\section{Data and methodology Data collection instrument}

Data were collected by means of a structured selfadministered online questionnaire, which was divided into three main sections. The first section included questions relating to the participants and their wine consumption behaviour. Screening questions ensured that respondents were above the legal South African alcohol drinking age of 18 years, were South African citizens and were wine consumers. In the second section, respondents were requested to rate the importance of a set of wine attributes as identified and used in previous studies (Casini et al., 2009; Chrysochou et al., 2012; Cohen, 2009). In addition to the 13 commonly used attributes that are known to influence consumers' winepurchasing behaviour, this study included another attribute, namely health benefits. As the health attribute has not been explicitly included in previous best-worst scaling (BWS) technique studies, it was included to establish whether South African wine consumers of different age cohorts would consider the health benefits (relative to the other attributes) when purchasing wine for own consumption. In this way, the study addressed calls by researchers (Chang et al., 2016; Higgins \& Llanos, 2015) for more research to be conducted on the possible importance of health in terms of behaviour surrounding wine purchasing and consumption. The final 14 attributes investigated in this study, therefore, were 'tasted the wine previously', 'someone recommended it', 'grape variety', 'I read about it', 'brand name', 'origin of the wine', 'matches my food', 'information on the shelf', 'attractive front label', 'information on the back label', 'promotional display in store', 'award', 'alcohol level below 13\%' and 'health benefits'.

To investigate the relative importance rating of the different wine attributes, the BWS technique was used in this study. The BWS technique was developed by Louviere and Woodworth (1990) and is an extension of Thurstone's (1927) random utility theory for paired comparisons (Cohen, 2009). This technique has been used in numerous wine-marketing studies (e.g. Casini et al., 2009; Chrysochou et al., 2012; Cohen, 2009; Mueller \& Rungie, 2009; Nunes, Madureira, Oliveira, \& Maduriera, 2016). One of the reasons for its popularity lies in the fact that it is an unbiased method that infers a ratio level importance scale, which allows for comparisons to be made across consumer segments (Cohen, 2009).
The 14 selected wine attributes were divided into 14 subsets of five items each, and the balanced incomplete block design method was used to ensure that each wine attribute that was tested appeared the same number of times (i.e. five times) in the questionnaire. The 14 different subsets were presented to the respondents and, for each subset, they were requested to select the attribute they considered most important when purchasing a bottle of wine for their own consumption, as well as the attribute they regarded as the least important. An example of a completed BWS subset can be seen in Table 1.

In the final section of the questionnaire, the demographic data (age, gender and place of residence) of the respondents were collected.

\section{Data collection}

A convenience sampling method was used to collect data from a target population of South African wine-drinking consumers. After obtaining the necessary ethical approval to collect data for the study, access was obtained to the South African member database of a large and well-established South African wine estate. Permission was obtained to send an invitation and a link to the electronic questionnaire to all the individuals on this database. In addition, permission was also obtained from a South African online wine retailer to post an invitation to take part in the study on the homepage of their website. In an attempt to increase the response rate, an incentive of a case of wine was offered to three respondents who completed the entire questionnaire. A total of 646 usable questionnaires were completed by South African wine consumers and were used for statistical analyses.

\section{Ethical consideration}

Research Ethics Committee, Human Research (Humanities), Stellenbosch University (SU-HSD-00454).

\section{Results and discussion \\ Characteristics and wine consumption behaviour of the total realised sample}

The respondents of the sample were predominantly female (61\%), whereas male respondents comprised 39\%. The age distribution ranged from 18 to older than 60 , with $38 \%$ of respondents being between the ages of 18 and 30 years, 22\% between the ages of 31 and 40 years, $17 \%$ between the ages of 41 and 50 years, $15 \%$ between the ages of 51 and 60 years and the remaining $8 \%$ older than 60 years.

TABLE 1: An example of a completed best-worst subset.

\begin{tabular}{llc}
\hline Most important & Attribute & Least important \\
\hline- & Origin of the wine & - \\
- & Matches my food & - \\
$\mathbf{X}$ & Information on the back label & - \\
- & Brand name & - \\
- & Alcohol level below 13\% & $\mathbf{X}$ \\
\hline
\end{tabular}


The following results were found for the wine consumption behaviour of the total realised sample. Most of the respondents (54\%) indicated that they consumed wine on a weekly basis, $27 \%$ noted that they consumed wine on a daily basis and 10\% drank wine once every 2 weeks. The largest proportion of the sample (50\%) reported that they consumed between one and six bottles of wine per month, 32\% consumed between one and three bottles of wine per month and $28 \%$ drank between four and six bottles of wine per month. A further $9 \%$ of respondents indicated that they consumed between 11 and 13 bottles of wine per month, whereas $15 \%$ indicated that they drank more than 13 bottles of wine per month.

\section{Wine consumption differences between age groups}

As explained earlier, a main objective of the study was to compare the wine consumption behaviour of two broad age groups. Respondents were thus categorised into a younger cohort (between the ages of 18 and $40 ; n=389$ ) and an older cohort (41 years and older; $n=257$ ).

The results indicated that, on average, the younger respondents consumed wine once every 2 weeks, whereas the older respondents consumed wine on a weekly basis. On average, the younger respondents consumed five bottles of wine per month, whereas the older consumers consumed eight bottles of wine per month. It therefore seems that, on average, the older consumers in this sample drank more wine than the younger consumers and also consumed wine more regularly. These findings are supported by previous literature that states that, in general, wine consumption and frequency tend to increase with age (Bruwer et al., 2012; Fountain \& Lamb, 2011). It is therefore possible to theorise that the aforementioned behaviour results from the experience older wine drinkers have gained over the years, as they have been exposed to the wine product for a longer period of time. The important conclusion can be made that it is very likely that the current cohort of younger wine drinkers (in many studies referred to as Generation $\mathrm{Y}$ wine drinkers) would remain loyal wine drinkers and also increase their volume of wine consumption as they get older (Fountain \& Lamb, 2011). This notion emphasises the importance of targeting and nurturing this potentially lucrative market.

\section{The importance of wine attributes: Results of the best-worst scaling technique}

As mentioned previously, the BWS technique was used in this investigation. According to Cohen (2009), it is relatively simple to use the BWS technique in wine business research, especially to conduct multicultural comparisons, as it avoids scale confounds. Cohen (2009) furthermore argues that the BWS technique provides better discrimination between attributes than traditional rating scale methods do.

Participants were requested to indicate the most and the least important wine attributes from subsets of five attributes from a total of 14 attributes. Each wine attribute could receive a BWS score of between -5 and +5 , as each attribute appeared five times across the subsets. A score of -5 implied that every time the wine attribute appeared, it was selected as the least important, and a score of +5 indicated that every time the attribute appeared, it was selected as the most important. The BWS score for each wine attribute was calculated and consequently tabulated.

Table 2 depicts the BWS scores for each wine attribute in terms of the complete sample of respondents (i.e. before dividing the sample into two age groups). It is evident from the table that the highest score $(+2.77)$ was for the attribute 'tasted the wine previously', whereas the lowest score $(-1.85)$ was obtained for the attribute 'alcohol level below 13\%'. The five most important attributes for the total sample were 'tasted the wine previously', 'someone recommended it', 'grape variety', 'brand name' and 'I read about it.' On the other hand, the five least important attributes were 'information on the back label', 'information on the shelf', 'health benefits', 'promotional display in store' and 'alcohol level below 13\%'.

To compare the two different age cohorts investigated in this study, the BWS scores for each group were consequently calculated. These scores are presented in Table 3 and graphically depicted in Figure 1.

From Table 3, it is evident that the most important attribute for the younger group was 'tasted the wine previously' $(+2.72)$, whereas the least important attribute for this group was 'alcohol level below 13\%' (-1.90). The older generation also rated their most important attribute as 'tasted the wine previously' (+2.79), but the least important attribute for this group was 'promotional display in store' (-2.27).

In addition to the BWS scores for the two age cohorts, independent sample $t$-tests were conducted to investigate whether there were any significant differences relating to the importance of wine attributes between the two age groups.

TABLE 2: Summary of the best-worst scaling scores of wine attributes $(N=646)$.

\begin{tabular}{lccc}
\hline Attribute & $\begin{array}{c}\text { Mean of individual } \\
\text { BWS score }\end{array}$ & SD of BWS & $\begin{array}{c}\text { Position of } \\
\text { importance } \\
\text { (most to least) }\end{array}$ \\
\hline Tasted the wine previously & 2.77 & 1.53 & 1 \\
Someone recommended it & 2.15 & 1.57 & 2 \\
Grape variety & 0.89 & 2.40 & 3 \\
Brand name & 0.69 & 1.83 & 4 \\
I read about it & 0.48 & 1.73 & 5 \\
Origin of the wine & 0.25 & 1.84 & 6 \\
Award & 0.14 & 1.87 & 7 \\
Matches my food & 0.12 & 2.23 & 8 \\
Attractive front label & -0.50 & 1.81 & 9 \\
Information on the back label & -0.69 & 1.72 & 10 \\
Information on the shelf & -1.33 & 1.26 & 11 \\
\hline Health benefits & -1.52 & 1.65 & 12 \\
Promotional display in store & -1.61 & 2.61 & 13 \\
Alcohol level below 13\% & -1.85 & 1.65 & 14 \\
\hline
\end{tabular}

BWS, best-worst scaling; SD, standard deviation. 
TABLE 3: Summary of the best-worst scaling scores of wine attributes for the two age cohorts.

\begin{tabular}{|c|c|c|c|c|c|}
\hline \multirow[t]{2}{*}{ Attribute } & \multicolumn{2}{|c|}{ Older cohort $(n=257)$} & \multicolumn{2}{|c|}{ Younger cohort $(n=389)$} & \multirow[t]{2}{*}{$t$-test $p$-value } \\
\hline & Mean of individual BWS score & SD of BWS & Mean of individual BWS score & Standard deviation of BWS & \\
\hline Tasted the wine previously & 2.79 & 1.62 & 2.72 & 1.48 & 0.67 \\
\hline Someone recommended it & 1.99 & 1.52 & 2.27 & 1.60 & 0.05 \\
\hline Grape variety & 1.44 & 2.17 & 0.52 & 2.48 & 0.00 \\
\hline Brand name & 0.70 & 1.71 & 0.70 & 1.91 & 0.98 \\
\hline I read about it & 0.91 & 1.67 & 0.21 & 1.70 & 0.00 \\
\hline Origin of the wine & 0.64 & 1.76 & 0.00 & 1.84 & 0.00 \\
\hline Award & 0.18 & 1.84 & 0.14 & 1.90 & 0.92 \\
\hline Matches my food & 0.08 & 2.18 & 0.15 & 2.27 & 0.62 \\
\hline Attractive front label & -0.93 & 1.67 & -0.21 & 1.84 & 0.00 \\
\hline Information on the back label & -0.72 & 1.61 & -0.67 & 1.79 & 0.70 \\
\hline Information on the shelf & -1.40 & 1.28 & -1.28 & 1.25 & 0.39 \\
\hline Health benefits & -1.59 & 1.67 & -1.47 & 1.63 & 0.41 \\
\hline Promotional display in store & -2.27 & 2.34 & -1.17 & 2.69 & 0.00 \\
\hline
\end{tabular}

BWS, best-worst scaling; SD, standard deviation.



FIGURE 1: Best-worst scaling scores for the two age cohorts.

When considering the most important attributes, significant differences were found for 'grape variety' $(p=0.00)$, in that the older cohort found this attribute more important than the younger cohort. Both the attributes 'I read about it' and 'origin of wine' (both $p=0.00$ ) were also deemed more important for the older cohort than for the younger cohort.

In terms of the least important attributes, results of the independent sample $t$-tests revealed that there was a significant difference in importance between the two groups relating to only one attribute, namely 'promotional display in store' $(p=0.00)$. Even though this attribute was not regarded as very important in their wine purchasing relative to other attributes, 'promotional display in store' was deemed more important for the younger group than it was for the older group.

\section{Conclusion and managerial implications}

Justification for this study is provided by the fact that once the total realised sample was split into the two broad age cohorts, there were not only similarities but also differences in the relative importance of the wine attributes considered when respondents purchased wine for their own consumption. The five most important attributes (in order of importance) for the younger cohort were identified as 'tasted the wine previously', 'someone recommended it', 'brand name', 'grape variety' and 'I read about it'. For the older cohort of respondents, the five most important attributes were 'tasted the wine previously', 'someone recommended it', 'grape variety', 'I read about it' and 'brand name'. Although both cohorts regarded the same attributes as the five most important, the difference in importance is evident. Both groups of older and younger wine consumers emphasised the importance of having tasted the wine previously and that someone recommended the wine to them. This finding corresponds with a number of previous studies in this regard (Chrysochou et al., 2012 [USA]; Cohen, 2009 [Australia]; Lategan et al., 2017 [South Africa]).

Wine industry professionals targeting South African wine consumers can focus on previous sensorial experiences (i.e. having tasted the wine previously) and wine recommendations, to increase the domestic sales and consumption of wines. The implication for winemarketing professionals is to create events or times where the consumer can have a direct, sensorial and personal experience with the wine. An example is to take advantage of special wine tastings, wine events and wine festivals. A wine-tasting assistant can, for example, be employed to introduce and invite potential customers to taste specific wines in a retail setting (e.g. a liquor store, supermarket or an airport duty-free shop) before they consider buying it. Furthermore, wine industry role players can encourage wine drinkers to visit and experience the tasting rooms of 
South African wine estates. This can be done by hosting events at wine estates by transforming a tasting room from a place where wine is explored into a vibrant venue that inspires people to bring more friends and spend time drinking and enjoying wine. An example is to offer lunches on wine estates, at special occasions such as Christmas Day, the Easter weekend, Mother's Day or Valentine's Day. This kind of exposure to wine can create memorable experiences that many consumers might want to share with friends and/or family on, for example, social media platforms such as Facebook and Instagram. A natural connection between the two most important wine attributes could therefore be formed, as wine consumers might be intrigued to also buy the wines that were recommended or spoken about by others. Wine professionals can also increase the awareness of their wines and brands by featuring in wine guides (e.g. Platter's Wine Guide) and wine magazines (e.g. WineLand) and by sharing relevant, engaging and up-todate content on, for example, social media platforms. Moreover, wine professionals can invite influential bloggers and journalists to their wine estates, taking them on informative tours and offering them wine tastings. This experience can encourage these delegates to write about the specific wine estates and their wines, which in turn can encourage wine consumers to visit these wine estates and/ or buy their wines. Wine marketers can also train and use other role players involved in the wine industry such as waiters at restaurants, sommeliers and wine cellar tasting room staff to establish the preferences and/or needs of potential wine consumers and recommend wines that could satisfy their specific needs.

Should wine industry role players wish to incorporate additional wine attributes into their wine-marketing strategies, the results imply that apart from taste and recommendations, stressing the brand name, grape variety and printed information (in that order of importance) can be considered when targeting younger (18-40 year old) age groups. Promotional activities can attend to brand and relationship building as well as increasing younger consumers' knowledge about wine in a simple and easy way to understand. Bringing wine brands to the younger consumer can increase the awareness of the brand by, for example, sponsoring events such as concerts and sport gatherings, which are often attended by the younger generation. Considering the older group (40 years and up), wine-marketing strategies can, apart from taste and recommendations, also emphasise the grape variety, provide printed information on different wines and focus on the wine brands (in that order of importance).

An important fact to keep in mind, however, is that the attributes 'grape variety' and 'printed information' were regarded as significantly more important for the older group than for the younger group of respondents. In addition to taste, recommendations and the brand name, wine industry professionals could therefore consider incorporating the grape variety and printed information only in marketing strategies for older consumers (40 years and up). On the other hand, wine industry professionals could consider only focusing or placing a stronger focus on the taste of wine, wine recommendations and the brand name when developing marketing strategies for younger (18-40 year old) consumers. Such a focused strategy could assist wine industry professionals to more accurately allocate limited marketing budgets to aspects that might have significant positive influences on the wine-buying behaviour of different consumer groups. It is furthermore suggested that, in terms of marketing strategies, wine industry professionals spend less time, effort and resources on the least important wine attributes. The findings of the study showed that the five least important attributes that the younger respondents would consider when buying a bottle of wine for their own consumption are 'alcohol level below $13 \%$ ', 'health benefits', 'information on the shelf', 'promotional display in store' and 'information on the back label'. The five least important attributes that the older group would consider were 'promotional display in store', 'alcohol level below 13\%', 'health benefits', 'information on the shelf' and 'attractive front label'. Of the least important attributes, four of the five attributes selected were similar for the two groups, even though the sequence of importance differed. A difference, however, was that for the younger cohort 'information on the back label' was selected as one of the five least important attributes, whereas the older cohort regarded 'attractive front label' as one of the five least important attributes.

A novel contribution of this study was to include the health attribute into the set of investigated wine attributes to establish whether wine consumers would consider the health benefits (relative to the other attributes) as important when purchasing wine for their own consumption. The results showed that neither of the age groups deemed health benefits as important when buying wine for their own consumption and that they would rather consider other wine attributes above the supposed health benefits that a particular wine might hold. This finding implies that, in the current South African context, wine marketers should pay less attention to the health benefits of wine and concentrate more on the wine attributes that are deemed more important by South African wine consumers when purchasing wine for their own consumption.

This study contributes to the limited published research on wine consumer behaviour based on wine attribute preferences in emerging markets. The findings of the study can assist role players (e.g. marketing managers) in the South African wine industry to make more informed strategic marketing decisions relating to their wine product, by considering the similarities and differences between the different age groups' preferences. Moreover, the marketing strategies should reflect the importance of the attributes derived from the BWS scores by optimising the attributes that were of high importance and focusing less on the attributes that South African wine consumers deemed less important. It is 
believed that by incorporating the results of this study into their marketing strategies, role players in the South African wine industry will be able to increase the domestic consumption of wine in this emerging wine-producing country.

\section{Limitations and suggestions for future research}

A limitation of the study pertains to the convenience sample used. Even though the study aimed to make inferences about the overall South African wine consumer, it is not possible to generalise the results entirely as the sample was not representative of the overall South African population. It is suggested that future follow-up studies should include larger, more representative national samples of the South African population. Another avenue of future research is to investigate whether the findings of this study are comparable with those of other emerging countries or whether the findings are country-specific. This is possible as the BWS technique allows for cross-country comparisons (Goodman, 2009).

This study's findings concur with various other BWS studies (e.g. Bernabéu, Díaz, Olivas, \& Olmeda, 2012; Chrysochou et al., 2012; Cohen, 2009; Lategan et al., 2017), in that the wine attribute 'alcohol level below 13\%' was not deemed very important by respondents when purchasing wine. Though the price of a wine was omitted from many previous BWS studies (on which the current study was based), it is an attribute that might play an instrumental role in the wine selection decision-making process especially for younger, less affluent consumers. A suggestion for future research therefore is thus to replace the attribute 'alcohol level below 13\%' with the attribute 'price of the wine'. A final suggestion for future research is that a technique such as the Kano analysis of customer satisfaction be performed to investigate consumer perceptions of wine attributes in more depth.

\section{Acknowledgements}

The authors wish to thank Prof. Martin Kidd for assisting with the statistical analysis of the data.

\section{Competing interests}

The authors declare that no competing interests exist.

\section{Authors' contribution}

A.F. conducted this study as part of her honours degree. C.P. was the supervisor. Both authors contributed equally to this manuscript.

\section{Funding information}

This research received no specific grant from any funding agency in the public, commercial or not-for-profit sectors.

\section{Data availability statement}

Data sharing is not applicable to this article as no new data were created or analysed in this study.

\section{Disclaimer}

The views and opinions expressed in this article are those of the authors and do not necessarily reflect the official policy or position of any affiliated agency of the authors.

\section{References}

Agnoli, L., Begalli, D., \& Capitello, R. (2011). Generation Y's perception of wine and consumption situations in a traditional wine-producing region. International Journal of Wine Marketing, 23(2), 176-192. https://doi.org/10.1108/17511061111143025

Barber, N., Almanza, A., \& Donovan, J. (2006). Motivational factors of gender, income and age on selecting a bottle of wine. International Journal of Wine Marketing, 18(3), 218-232. https://doi.org/10.1108/09547540610704774

Barber, N., Dodd, T., \& Ghiselli, R. (2008). Capturing the younger wine consumer, Journa of Wine Research, 19(2), 123-141. https://doi.org/10.1080/09571260802622225

Bernabéu, R., Díaz, M., Olivas, R., \& Olmeda, M. (2012). Consumer preferences for wine applying best-worst scaling: A Spanish case study. British Food Journal, 114(9), 1228-1250. https://doi.org/10.1108/00070701211258790

Bruwer, J., Lesschaeve, I., \& Campbell, B.L. (2012). Consumption dynamics and demographics of Canadian wine consumers: Retailing insights from the tasting room channel. Journal of Retailing and Consumer Services, 19(1), 45-58. https:// doi.org/10.1016/j.jretconser.2011.08.008

Bruwer, J., Saliba, A., \& Miller, B. (2011). Consumer behavior and sensory preference differences: Implications for wine product marketing. Journal of Consumer Marketing, 28(1), 5-18. https://doi.org/10.1108/07363761111101903

Casini, L., Corsi, A.M., \& Goodman, S. (2009). Consumer preferences of wine in Italy. Applying best worst scaling. International Journal of Wine Business Research, 21(1), 64-78. https://doi.org/10.1108/17511060910948044

Chang, K.J., Thach, L., \& Olsen, J. (2016). Wine and health perceptions: Exploring the impact of gender, age and ethnicity on consumer perceptions of wine and health. Wine Economics and Policy, 5(2016), 105-113. https://doi.org/10.1016/j.wep. 2016.09.001

Chrysochou, P., Krystallis, A., Mocanu, A., \& Lewis, R. (2012). Generation Y preferences for wine: An exploratory study of the US wine market applying the best-worst scaling. British Food Journal, 114(4), 516-528. https://doi.org/10.1108/00070701211219531

Cohen, E. (2009). A cross-cultural comparison of choice criteria for wine in restaurants. International Journal of Wine Business research, 21(1), 50-63. https://doi.org/ 10.1108/17511060910948035

Cohen, E. (2009). Applying best-worst scaling to wine marketing. International Journal of Wine Business research, 21(1), 8-23.

Conradie, C. (2019). SA wine industry turns a new corner. Retrieved from https:// vinpro.co.za/sa-wine-industry-turns-a-new-corner/

Ellis, D., \& Thompson, M. (2018). The effect of wine knowledge type on varietyseeking behaviour in wine purchasing. Journal of Wine Research, 29(2), 71-86. https://doi.org/10.1080/09571264.2018.1471393

Fountain, F., \& Lamb, C. (2011). Generation Y as young wine consumers in New Zealand: How do they differ from generation X? International Journal of Wine Research, 23(2), 107-124. https://doi.org/10.1108/17511061111142981

Fracassetti, D., Bottelli, P. Corona, O., Foschino, R., \& Vigentini, I. (2019). Innovative alcoholic drinks obtained by co-fermenting grape must and fruit juice. Metabolites, 9(5), 86. https://doi.org/10.3390/metabo9050086

Goodman, S. (2009). An international comparison of retail consumer wine choice. International Journal of Wine Business Research, 21(1), 41-49. https://doi.org/ 10.1108/17511060910948026

Higgins, L., \& Llanos, E. (2015). A healthy indulgence? Wine consumers and the health benefits of wine. Wine Economics and Policy, 4(2015), 3-11.

Hirche, M., \& Bruwer, J. (2014). Buying a product for an anticipated consumption situation. International Journal of Wine Business Research, 26(4), 295-318. https://doi.org/10.1108/IJWBR-01-2014-0007

Histro, H., \& Kuhar, A. (2015). Subjective knowledge as a determinant of young adult consumers wine behaviour. British Food Journal, 117(12), 2931-2945.

Lategan, B.W., Pentz, C.D., \& Du Preez, R. (2017). Importance of wine attributes: A South African generation Y perspective. British Food Journal, 119(7), 1536-1546. https://doi.org/10.1108/BFJ-09-2016-0420

Lockshin, L., \& Corsi, A.M. (2012). Consumer behaviour for wine 2.0: A review since 2003 and future directions. Wine Economics and Policy, 1(2012), 2-23.

Louviere, J.J. \& Woodworth, G.G. (1990). Best worst scaling: a model for largest difference judgments, working paper, Faculty of Business, Edmonton: University of Alberta.

Marinelli, N., Fabbrizzi, S., Sottini, V.A., Sacchelli, S., Bernetti, I., \& Menghini, S. (2014) Generation $Y$, wine and alcohol. A semantic differential approach to consumption analysis in Tuscany. Appetite, 75(2014), 117-127. https://doi.org/10.1016/j. appet.2013.12.013 
McGarry Wolf, M., Higgins, L.M., Wolf, M.J., \& Qenani, E. (2018). Do generations matter for wine segmentation? Journal of Wine Research, 29(3), 177-189.

McGovern, P., Jalabadze, M., Batiuk, S., Callahan, M.P., Smith, K.E., Hall, G.R., ... Lordkipanidze, D. (2017). Early Neolithic wine of Georgia in the south causasus. Retrieved from http://www.pnas.org/content/114/48/E10309

Mehta, R., \& Bhanja, N. (2018). Consumer preferences for wine attributes in an emerging market. International Journal of Retail \& Distribution Management, 46(1), 34-48. https://doi.org/10.1108/IJRDM-04-2017-0073

Mishra, G.D., McNaughton, S.A., Bramwell, G.D., \& Wadsworth, M.E. (2006) Longitudinal changes in dietary patterns during adult life. British Journal of Nutrition, 96(4), 735-744.

Mueller, S., \& Rungie, C. (2009). Is there more information in best-worst choice data? International Journal of Wine Business Research, 21(1), 24-40. https://doi. org/10.1108/17511060910948017

Murphy, H.L. (1999). Xers' vintage point. Marketing News, 33(5), 1-2.

Nissen, K. (2012). Influences on wine purchases: A comparison between Millennials and prior generations. Unpublished Manuscript, Faculty of the Agribusiness Department, California Polytechnic State University Retrieved from https://pdfs. semanticscholar.org/bf92/af0cde7f7718a081f0dcce73f824b03ec452.pdf.

Nunes, F., Madureira, T., Oliveira, J., \& Maduriera, H. (2016). The consumer trail: Applying best-worst scaling to classical wine attributes. Wine Economics and Policy, 5(2), 78-86. https://doi.org/10.1016/j.wep.2016.10.002

OIV. (2019). State of the vitiviniculture world market: State of the sector in 2018 Retrieved from http://www.oiv.int/public/medias/6679/en-oiv-state-of-thevitiviniculture-world-market-2019.pdf.
Olsen, J.E., Thach, L., \& Nowak, L. (2007). Wine for my generation: Exploring how US wine consumers are socialised to wine. Journal of Wine Research, 18(1), 1-18. https://doi.org/10.1080/09571260701526816

Orth, U.R., \& Krška, P. (2002). Quality signals in wine marketing: The role of exhibition awards. International Food and Agribusiness Management Review, 4, 385-397.

Pomarici, E., Lerro, M., Chrysochou, P., Vecchio, R., \& Krystallis, A. (2017). One size does (obviously not) fit all: Using product attributes for wine market segmentation Wine Economics and Policy, 6(2017), 98-106. https://doi.org/10.1016/j.wep. 2017.09.001

SAWIS. (2018). SA Wine Industry 2018 Statistics Nr 43. Retrieved from http://www. sawis.co.za/info/download/Book_2018_statistics_year_english_final.pdf.

Soleas, G.J., Diamandis, E.P., \& Goldberg, D.M. (1997). Wine as a biological fluid: History, production, and role in disease prevention. Journal of Clinical Laboratory Analysis, 11, 287-313. https://doi.org/10.1002/(SICI)1098-2825(1997)11:5<287: AID-JCLA6>3.0.CO;2-4

South African Government. (n.d.). BRICS - Brazil, Russia, India, China, South Africa Retrieved from https://www.gov.za/about-government/brics-brazil-russia-indiachina-south-africa-1.

Thurstone, L.L. (1927). A law comparative judgment. Psychological Review, 34, 273-286.

Wesgro. (2017). Wine fact sheet. Retrieved from http://www.wesgro.co.za/pdf repository/Wine $\% 2$ Fact $\% 2$ Sheet $\% 20-\% 20$ Mar $\% 202017 \% 20-\% 20$ Final.pdf.

WOSA. (2018). Three centuries of Cape wine. Retrieved from https://www.wosa.co.za/ The-Industry/History/Three-Centuries-of-Cape-Wine/. 